\title{
Training in practical optics: from university to secondary school
}

C. Perez, M. I. de la Rosa, A. de Frutos, S. Mar, J. González Vizmanos, et al.

C. Perez, M. I. de la Rosa, A. M. de Frutos, S. Mar, J. González Vizmanos, T. Manzano, "Training in practical optics: from university to secondary school," Proc. SPIE 9664, Ninth International Topical Meeting on Education and Training in Optics and Photonics, 966420 (24 October 2005); doi: $10.1117 / 12.2207761$

SPIE Event: Ninth International Topical Meeting on Education and Training in Optics and Photonics, 2005, Marseille, France 


\title{
Ref ETOP078
}

\section{Training in Practical Optics: From University to Secondary School}

\author{
C. Pérez, M.I. de la Rosa, A.M. de Frutos, S. Mar, J. González Vizmanos, T. Manzano
}

\begin{abstract}
s
Optics Group in the Faculty of Science at Valladolid University collaborates in training secondary schools teachers in several aspects of Optics. This work is the result of a continuous collaboration (since 1998) between our University and Ministry of Education. In our country, long-life education of teachers is led by specific Centers depending on the Ministry: CFIE. Our responsibility in this collaboration has consisted in planning and giving different courses. As we have detected a lack of practical skills in the first level university students, the aim of our collaboration has been to show practical aspects of Optics changing blackboard by laboratory experiences
\end{abstract}

\section{Summary}

The Optics Group in the Faculty of Science at Valladolid University is not only responsible for the education in different university studies such as Physics, Chemistry, or Optometry, but also collaborates in training secondary schools teachers in several aspects of Optics.

This work is the result of a continuous collaboration (started in the year 1998) between our University and the Ministry of Education (Ministerio de Educación y Cultura). In our country, long-life education of primary and secondary teachers is led by specific Centers depending on the Ministry: Centros de Formación del Profesorado e Innovación Educativa (CFIE). At least one of those centres exists in each province. Our responsibility in this collaboration has consisted in planning and giving courses in different provinces of the region.

In order to define the main goals of our work, we have verified that in the curricula of Secondary Education there are included the basics of Geometrical and Physical Optics. However, we have detected a lack of practical skills in the first level university students. For this reason and due to the short duration of the courses, practical aspects of Optics have been the aim of our collaboration, i.e. to substitute blackboard by laboratory experiences. These courses are held in secondary schools, this means in the real stage; and to reach higher effectiveness, we have designed all the experiences with the basic equipment, that is found in almost every secondary school all over the country.

The previous considerations result in the main aims of the collaboration which are the following:

- To contribute to the scientific actualization in Optics of secondary school teachers

- To do straightforward laboratory experiences easy to translate to the classroom

- To give strategies and methodologies that contribute to improve the teaching of experimental Optics

- $\quad$ To give information available via Internet in all aspects connected with Optics and Science in general

- $\quad$ To deepen in new aspects of the curriculum of Optics 
We have taken part in two different types of courses: some of them devoted to Optics and some others in which Optics was only a part of a more general course of Physics and Chemistry. As an example we provide with a brief program of a typical Optics course (40 hours duration), and at the Conference we will show a more detailed scheme:

- $\quad$ Geometric Optics I: Fundamentals

- $\quad$ Geometric Optics II: Instruments

- Wave Optics I: Fundamental and Instruments

- Modern Optics

At the end of each course, CFIE organizes a final written evaluation in which school teachers can express freely their opinions about all aspects of it. Normally teachers seem to be happy with all they have learned, but they doubt if they will be able to put all this knowledge into practice. In future collaborations, we plan to do a posterior research of the activities of participants, in order to know the effectiveness of our teaching, and even, if necessary, to give subsequent help. 